\title{
Effects of electronic outlining on students' argumentative writing performance
}

Citation for published version (APA):

De Smet, M., Broekkamp, H., Brand-Gruwel, S., \& Kirschner, P. A. (2011). Effects of electronic outlining on students' argumentative writing performance. Journal of Computer Assisted Learning, 27(6), 557-574.

https://doi.org/10.1111/j.1365-2729.2011.00418.x

\section{DOI:}

10.1111/j.1365-2729.2011.00418.x

Document status and date:

Published: 01/12/2011

Document Version:

Peer reviewed version

Please check the document version of this publication:

- A submitted manuscript is the version of the article upon submission and before peer-review. There can be important differences between the submitted version and the official published version of record. People interested in the research are advised to contact the author for the final version of the publication, or visit the DOI to the publisher's website.

- The final author version and the galley proof are versions of the publication after peer review.

- The final published version features the final layout of the paper including the volume, issue and page numbers.

Link to publication

\section{General rights}

Copyright and moral rights for the publications made accessible in the public portal are retained by the authors and/or other copyright owners and it is a condition of accessing publications that users recognise and abide by the legal requirements associated with these rights.

- Users may download and print one copy of any publication from the public portal for the purpose of private study or research.

- You may not further distribute the material or use it for any profit-making activity or commercial gain

- You may freely distribute the URL identifying the publication in the public portal.

If the publication is distributed under the terms of Article 25fa of the Dutch Copyright Act, indicated by the "Taverne" license above, please follow below link for the End User Agreement:

https://www.ou.nl/taverne-agreement

Take down policy

If you believe that this document breaches copyright please contact us at:

pure-support@ou.nl

providing details and we will investigate your claim.

Downloaded from https://research.ou.nl/ on date: 26 Apr. 2023 
Running head: OUTLINING AND ARGUMENTATIVE WRITING

Effects of Electronic Outlining on Students' Argumentative Writing Performance M. J. R. de Smet

Open University of the Netherlands

H. Broekkamp

Utrecht University / University of Amsterdam, The Netherlands.

P. A. Kirschner, S. Brand-Gruwel

Open University of the Netherlands

Correspondence should be addressed to M. J. R. de Smet, Centre for Learning Sciences and Technologies, Open University of the Netherlands, PO Box 2960, 6401 DL Heerlen, The Netherlands. Email: milou.desmet@ou.nl

This research project was generously funded by the Kennisnet Foundation, the knowledge centre for information and communication technologies and education in the Netherlands. 


\begin{abstract}
This study examined the effect of electronic outlining on the quality of students' writing products and how outlining affects perceived mental effort during the writing task. Additionally, it was studied how students appropriate and appreciate an outline tool and whether they need explicit instruction in order to engage in planning. To answer these questions, the writing products and self-report data from 34 tenth-grade students of a Dutch pre-university school were analyzed. Students wrote two similar argumentative texts with or without an outline tool. Results show that electronic outlining improves the quality of students' argumentative texts and decreases mental effort. Answers to a retrospective questionnaire showed that a short instruction on the outline tool was sufficient for students to understand its working and that most students experienced the tool as beneficial. Finally, results indicate that without specific instruction on text planning, students hardly devote any time to this important aspect of writing.
\end{abstract}

Keywords: Electronic outlining, outline tool, argumentative text, writing, text structure, mental effort, writing process, writing performance 


\section{Effects of Electronic Outlining on Students' Argumentative Writing Performance}

During the last twenty years, personal computers have taken on an ever increasing role in education. Students regularly use general and specific computer tools to search, represent and process information. Those tools are often readily available in standard software that is installed on their computer (e.g., word processor, spreadsheet, internet browser). In fact, most computers include so many tools that many of them remain unused or unknown, even when they are potentially helpful (Collins \& Halverson, 2010).

One might think that tools which could significantly impact academic performance and learning would be used in educational settings either by students or their teachers. Moreover, one might think that educators would include instruction on how to use these tools in the regular school curriculum. Unfortunately, this is not the case.

Although today's students are often considered to be 'digital natives' (Prensky, 2001), "it appears they do not recognize the enhanced functionality of the applications they own and use” (Bullen, Morgan, Belfer, \& Qayyum, 2008; p. 7.7). Margaryan, Littlejohn, and Vojt (2010) reported that when used for learning, technology is mostly for passive information consumption (e.g., Wikipedia ${ }^{\circledR}$ ) or for downloading lecture notes. Furthermore, teachers are often not very digitally literate and/or do not know how to use available tools in an educational setting. Säljö (2010) noted that "digital curriculum materials and multimedia resources have not been able to assert themselves as part of regular educational practices to the extent that some predicted they would" (p. 54). Teachers rarely integrate computer tools into their education and thus students are not introduced to the wide range of their computer's possibilities.

This study focuses on a specific type of readily available tools, namely tools for outlining. Although researchers have emphasized the advantages of computer tools that support outlining for students' learning and writing (Flower \& Hayes, 1984; Haas, 1989; 
Kozma, 1991; Walvoord, Anderson, Breihan, McCarthy, Robison, \& Sherman, 1995), these tools appear to be rarely used and hardly known among students and/or teachers.

\section{Outlining}

Walvoord et al. (1995) define an outline as "a written vertical list of ideas or information in the sequence that the writer intends for the final piece of writing. Outlining is the process of producing this written artifact" (p. 400). What is here called an artifact, could also be called a plan which prepares the maker for an actual task or action environment (Hayes \& Nash, 1996). This action environment could be considered more broadly than Walvoord et al. do when they use the designation "piece of writing". Indeed, the written lists of ideas that constitute outlines may prepare one for the production of various written or oral texts, including essays, reports, presentations or even hypertexts. Like plans in general, outlines allow their makers to think about the structure of a desired product or the steps according to which this product is to be established (Hayes \& Nash; Miller, Galanter, \& Pribram, 1960). Generally speaking, an outline is a list of items, organized according to a consistent principle whereby each item may be divided into additional sub items (University of Chicago, 2003).

Traditionally, outlines are produced with pen-and-paper as tools. Currently, writers can profit from electronic tools for outlining incorporated in standard software on their computers such as in MS Word ${ }^{\circledR}$, Corel $^{\circledR}$, Word Perfect ${ }^{\circledR}$ and Star Office ${ }^{\circledR}$. These outline tools help writers in at least three ways (see Price, 1997) in that they (1) contribute to gaining a clear visualization of the global text structure, (2) enable users to fold or unfold parts of the text produced so far and thus focus attention on parts of the text that temporary need attention, and (3) allow writers to easily adapt the outline and the text structure.

In the literature, various reasons have been given for expecting beneficial effects of outlining. In a theoretical analysis on planning in writing, Hayes and Nash (1996) suggest that 
outlining provides writers with a material planning environment in which they think and act in flexible ways with relatively few costs of actions. Walvoord et al. (1995) report that outlines may help students to organize their texts, generate ideas and texts, apply a hierarchical structure to these ideas, revise them and coordinate their writing process. Erkens, Jaspers, Prangsma, and Kanselaar (2005), suggest that outlining may help writers with the linearization of ideas for text genres for which the ordering of ideas is not self evident. They see solving this linearization problem as crucial for writing argumentative texts (see also Coirier, Andriessen, \& Chanquoy, 1999; McCutchen, 1987).

However, outlining may have contra-productive effects when students use their lists of ideas too rigidly and do not allow for flexible adjustment of outlines during writing (Hayes \& Flower, 1986). Also, the appropriation process of using outlines or an outlining tool might distract students from the real goal of writing a text. Nevertheless, this should not obscure the fact that outlining has proven to be the most consistently successful planning strategy for writing (Walvoord et al., 1995) and that the outlining strategy could with little effort be taught and executed by students who have little or no experience with outlining or its underlying strategy of text planning (cf. Galbraith \& Torrance, 2004).

\section{The organization of the writing process}

Writing is a challenging cognitive activity consisting of different processes and sub processes. According to Flower and Hayes (1981), the writing process can be subdivided into three cognitive processes: planning, translating and reviewing. These three processes do not follow in a strict order but can occur at any point of the writing process. Moreover, they interact extensively with one another. One of the most important characteristics of the writing process is its non-linear, cyclic character. Writing is a recursive process in which the writer alternates the different processes from beginning to end (Flower \& Hayes). 
However, the process of writing is constrained by the writers' limited attentional capacity (Kahneman (1973) in Kellogg, 1988). Consequently, writers may have problems allocating sufficient attention to planning, translating and reviewing a text. Writers may profit from using cognitive strategies such as outlining because it corresponds directly to the cognitive components of the composing process. Preparing a written outline stimulates writers to focus on the planning process by reflecting on the text's organization and structure, while the translating and the revision process are temporary ignored (Kellogg). Subsequently, the tool enables the writer to focus on non-planning processes while translating. This separate management of different sub-processes might reduce a writer's mental effort by circumventing attentional overload. Mental effort is seen as the amount of capacity or resources that is needed to organize the task demands.

Kellogg (1988) examined the mental effort expended during each of the sub processes (i.e. planning, translating, reviewing) by using directed retrospection and secondary-task reaction times. Students had to react as quickly as possible to auditory signals prior to reporting the process in which they were engaged. Based on the reaction times, effort scores were calculated for the different processes. This enabled examination of whether outlining helped students to control attention allocation in order to reduce attentional overload. Results of this study show that outlining alleviated attentional overload by enabling the writer to focus attention to a single sub-process a time.

Outlining is not the only type of text planning that may be effective. As indicated by Galbraith and Torrance (2004) and Kozma (1991), students may engage in planning by strategies other than outlining. Depending on their writing style or level of writing proficiency, students may prefer other strategies such as drafting or concept mapping over outlining. Text planning is traditionally part of a student's regular curriculum, beginning in elementary school. Students are taught - independent of the strategy employed - to plan 
before elaborating their texts. In other words, one might assume that students with or without using the outline tool, would use a planning strategy to write their texts. However, not much is known as to whether students spontaneously engage in such planning.

It might also be that students need explicit instruction to use the outline tool or, in planning strategies in general, to engage in text planning at all. The question then is how much support (i.e. instruction) students need to use the tool and to use it properly. As 'digital natives', students are said to be quick in discovering the technical use of new computer tools and making quick decisions about their appropriateness (Turner \& Katic, 2009). However, it remains to be seen how much instruction students need to use and appropriate the tool in optimal ways.

\section{This study}

The study presented here investigates the effects of a brief tool instruction and planning and writing a text with an electronic outline tool on the quality of students' argumentative texts. Based on prior studies on outlining (Kozma, 1991; Walvoord et al., 1995), it is expected that the use of the tool, including a brief instruction on how to use the outline function in a word processor (i.e., MS Word ${ }^{\circledR}$ ), will lead to a text improvement for most students. In addition, it is expected that repeated use of the outline tool will lead to further improvement of text quality because of students' optimization of tool usage. Based on Kellogg's research on writing and cognitive load (2008), it is hypothesized that using an outline tool will decrease experienced cognitive load while writing the text. Cognitive load refers to the amount of mental effort a learner expends and is a function of the number of novel elements that need to be kept in working (i.e., short-term) memory and the degree of interaction between those novel elements (Kirschner, 2002). Moreover, the present study seeks to determine whether students appropriate and appreciate (using) the outline tool. Finally, it investigates whether students need explicit instruction to get them to use a planning 
strategy or if they engage spontaneously in text planning.

This leads to the following research questions:

1. Does using an electronic outline tool with a brief instruction improve student writing performance?

2. If so, does repeated use of an electronic outline tool further improve student writing performance?

3. Does using an outline tool decrease students' perceived mental effort?

4. Do students appropriate and appreciate working with the outline tool?

5. Do students spontaneously engage in text planning when they are not explicitly instructed to do so?

\section{Method}

\section{Participants}

Participants in this experiment were 34 Dutch tenth-grade students from three preuniversity history classes. The group consisted of 16 male and 18 female participants between the age of 15 and $17(M=15.66 ; S D=0.60)$. Participation in the experiment was both compulsory and rewarded by a gift certificate of 10 euro.

\section{Materials}

\section{Writing Tasks}

Students carried out two argumentative writing tasks about two current, muchdiscussed topics (i.e, a populist, right-wing politician and charging for healthcare insurance based on lifestyle). Apart from the specific topics, the tasks were kept as similar as possible. The main principles of argumentative writing and text structuring that are assessed in this study are independent of the specific issues and are, thus, equivalent for both tasks. 
Argumentative writing was common for students, who had received instruction in this genre as part of their regular curriculum in the three months prior to the experiment. For each task, 75 minutes were given to write a text of 600 to 800 words. Writing tasks of this substantial size were chosen, because it was assumed that outlining is more useful for longer texts.

Students carried out both writing tasks individually in the schools' computer room with Microsoft Office Word $2007^{\circledR}$; the word processor used in the school. The researcher and the students' own teacher were present at all times.

The tasks were given via a written instruction which introduced the topic and informed students about the required product characteristics (i.e., genre, text length), procedure and available time. In addition, a short prompt was added about the required argumentative text structure (i.e., defend a standpoint with arguments and address counter arguments). A pilot study revealed that some students needed these prompts to activate their previously acquired knowledge of the argumentative text genre (cf. Kozma, 1991).

\section{Outline tool}

The tool used in the experiment was the outline function embedded in the 'view' menu in

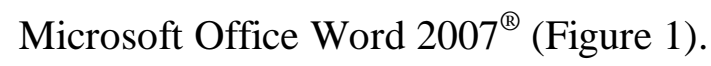

\section{[Insert Figure 1 here]}

This electronic outline tool incorporates the three functions described earlier. It (1) helps students to hierarchically visualize the global text structure, (2) enables them to fold and unfold parts of the text produced to focus attention on text parts needing attention, and (3) allows easy adaptation of the outline and text structure.

\section{Tool instruction}

Prior to the first writing task with outlining, students received a 10-minute training in 
which the tool and its working were explained. Care was taken to restrict this training to the technical tool use and not on how to integrate outlining with writing an argumentative text. Tool instruction was given centrally by the first author and was supported by a digital projector. The outline tool was demonstrated through an example where the hierarchical structure of a house was described in situ (Figure 2).

\section{[Insert Figure 2 here]}

While demonstrating the tool, the various buttons available and their function were explained. The demonstration was followed by a 5-minute practice session where students individually used the outline tool to describe their own homes. When needed, the researcher provided explanations of tool use.

\section{Questionnaire concerning control variables}

Before performing the first writing task, students completed a questionnaire on their skills, prior knowledge, self-efficacy and writing styles. The self-report questionnaire consisted of four components which inquired about student's (1) computer activities, (2) knowledge of the argumentative text genre, (3) use of news media, and (4) usual writing styles.

Questions on computer activities are partly based on the questionnaire from Leijten (2007). Students indicated since how many years and how often they work with a computer and word processor. They also indicated for 12 word processor writing functions (e.g, generating a table of contents, headings, outline function) whether or not they had used it before.

Questions concerning students' knowledge of argumentative text structure were based on a self-efficacy test for argumentative writing developed by Braaksma, Rijlaarsdam, and 
van den Bergh, (2009). Using a 5-point Likert scale (instead of the original 100-point scale used by Braaksma et al.) students indicated, for instance, the degree to which they "can support [their] standpoint with strong arguments". The scale consisted of 13 items. The reliability coefficient for this scale in our study was $\alpha=.88$ which can be considered as very good (DeVellis, 1991).

Questions about news media use were developed to determine students' general knowledge and interest in current events. Students were asked about their use of different news media such as newspapers, teletext, Internet, and magazines. For each medium, students could indicate whether and how often they used it varying from "I never use this medium" to "I use this medium several times a day".

Questions about students' writing process were based on a questionnaire developed by Kieft (2006) on students' usual writing strategies. Using a 5-point Likert scale, students indicated to what extent they usually engage in planning (four items, $\alpha=.60$ ) and revising activities (six items, $\alpha=.60$ ). This level of reliability is considered to be the boundary for acceptability (DeVellis, 1991) and thus results should be taken with caution. An example of a planning question is: "Before writing a text, I write down some notes and elaborate them later." An example of a revision question is "Usually I rewrite and revise my text at least once".

\section{Questionnaire on perceived mental effort}

After each writing task, students completed a questionnaire about their perceived mental effort while working on the argumentative text. To measure mental effort, students indicated on a 5-point Likert scale how much mental effort the writing task had cost them $(1=$ very little effort, $5=$ very much effort $)$. The choice to measure mental effort by means of a rating scale was based on Gopher and Braune's (1984) findings that subjects are able to introspect on their cognitive processes and have no problem rating the experienced mental 
effort on a numerical scale. The arrangement of our rating scale is based upon the 9-point subjective cognitive load scale developed by Paas (1992). It was reduced to five points based upon the results from our pilot study in which students reported problems evaluating the distinction on a 9-point scale. In addition, students indicated on a 5-point Likert scale how much mental effort they experienced on different aspects of the writing task such as determining a strategy, setting up a structure, formulating content and considering reader orientation.

\section{Questionnaire on tool use and appreciation}

Following each writing task in which the outline tool was used, a questionnaire was administered to measure students' tool appropriation and appreciation. The questionnaire consisted of eight items. Examples are: "Did you immediately understand how to use the outline tool?"; "Would you use the outline tool in subsequent writing tasks?".

\section{Questionnaire on the writing process}

Students reported after each writing task how they organized their writing process during the 75 minutes-session of performing their writing tasks. Students indicated here to what percentage of the total process time $(75$ minutes $=100 \%)$ they engaged in planning, formulating and revising their texts. Students who used the outline tool also included the first 15 minutes of merely outlining in their division of the total process-time. These data provide information about the extent to which students spontaneously engage in text planning, as they had learned to do in class, when not explicitly instructed to do so.

\section{Design and Procedure}

This study had a combined within-subjects and between-subjects design in which two conditions were compared. In each condition, students carried out two similar writing tasks, with an interval of one week. According to the design (Figure 3), students were or were not 
required to make an outline before elaborating their full text.

[Insert Figure 3 here]

This combined design allowed determination of the effects of electronic outlining on writing performance as measured by text quality while controlling for possible differences in competence between the two experimental conditions (i.e., a risk in a between-subjects design) and possible learning effects of repeatedly performing a writing task (i.e., a problem in a within-subjects design). In other words, this design filters out unintended effects that could interfere with the effect of planning and writing with an outline tool. Moreover, it allowed the determination of the effect of repeated experience with the outline tool.

Students were randomly assigned to Condition $\mathrm{O}-\mathrm{O}+(\mathrm{n}=18)$ or Condition $\mathrm{O}+\mathrm{O}+$ $(\mathrm{n}=16)$. Eventually, 14 students in the O-O+ condition performed both Task 1 and Task 2 , whereas two students in this condition only performed Task 1 and two students only performed Task 2. In the $\mathrm{O}+\mathrm{O}+$ condition, all students performed Task 1 and 13 of them also performed Task 2 .

Students in the O-O+ condition were instructed that they had 75 minutes to write an argumentative text (Task 1) as they had learned to do earlier in class. Students had learned how an argumentative text should be organized and how they could use planning strategies to compose their texts. They received the exact same written assignment (i.e., the same information and the same constraints) as students in the $\mathrm{O}+\mathrm{O}+$ condition apart from the explicit instruction to use the outline tool as a specific planning strategy.

For tasks that required the use of the outline tool, students were instructed to spend the first 15 minutes on outlining only and then write the full text in the remaining 60 minutes. An explicit subdivision of the writing task was chosen because it was assumed that using the 
outline tool was new for students. Without procedural facilitation, students would risk difficulties using the tool and managing their writing time (cf. Bereiter \& Scardamalia, 1987). Students who were not instructed to use the outline tool, did not receive explicit instruction to subdivide their writing task and were less restricted in what type of planning strategy they used and how long they would engage in planning. This allowed measurement of the extent to which these students would spontaneously devote time on the planning process.

\section{Data Analyses}

\section{Text quality}

To assess text quality, an assessment protocol developed by Erkens, Kanselaar, Prangsma and Jaspers (2002) for assessing argumentative text-quality was adapted and applied. The assessment distinguishes the degree to which students (1) correctly and completely establish a text structure, (2) clearly present this structure and (3) produce a complex, elaborated argumentation (see Appendix 1 for the scoring procedure). A high score on these three characteristics indicates a qualitatively good text.

Credit for Text Structure was given when students distinguished an introduction, text body and conclusion. Moreover, they needed to elaborate the different characteristics of each text part such as presenting arguments supporting their viewpoint and presenting and refuting counterarguments in the text body. Students could receive a maximum score of 1 point for a title (present $=1$, absent $=0$ ). For introduction, body and conclusion, students could respectively obtain maximum scores of 6,5 and 4 points. The maximum total score on text structure was 16.

Credit for structure presentation was given when students established an explicit presentation of the argumentative structure (i.e., distinguished paragraphs, used connectives and anaphors) and showed that they had taken the reader into account. This measure allows 
determining whether electronic outlining leads to a better argumentative structure and a more adequate use of linguistic structures such as connectives and anaphors (Chanquoy, 1996). The maximum total score on structure presentation was 14 .

The total number of (sub) arguments used in the final texts were calculated, as this was seen as an indication of students' ability to produce complex argumentation. Also, to make a fair comparison, the number of arguments students produced per minute of writing time was calculated. Moreover, the hierarchical elaboration of arguments was calculated. For each (elaborated) main argument, students could obtain 0,1 or 2 points $(0=$ a main argument is presented without any elaboration, 1 = a main argument is elaborated with at least one sub argument, 2 = main arguments are elaborated with at least one sub-sub argument). In other words, the further the argument was hierarchically elaborated, the higher the score.

Hypotheses concerning effects of electronic outlining on the main dependent variables (i.e., degree of structure, structure presentation, number of arguments, mental effort, tool appropriation and appreciation) were tested by means of univariate ANCOVAs for betweensubject comparisons. In the case of the within subjects comparisons, Paired Samples $t$-tests (one-tailed; $p<.05$ ) were used. A one-tailed analysis was used since an improvement in text quality and an decrease in perceived mental effort was expected. Moreover, possible topic effects were controlled by means of repeated measures.

All texts were independently scored by the first author and a research assistant who had a masters degree in linguistics. Inter-rater reliability on the coding task was measured with Cohen's kappa and an inter-rater agreement percentage. Table 1 gives an overview of the kappas and the correlations between the scores of the two raters. For 'Text Structure', 'Structure presentation', 'Number of arguments' and 'Hierarchical elaboration of arguments' only the correlation was calculated because the variables were counted instances instead of codes. 
[Insert Table 1 here]

As can be seen, mostly a substantial to (almost) perfect agreement (Landis \& Koch, 1977) could be determined between the evaluations of the two raters. Only the hierarchical elaboration of arguments has an insufficient level of agreement. Therefore, this variable was excluded from the results.

\section{Results}

\section{Control Variables}

Before presenting the data analysis to answer the central research questions, the values of the control variables are presented. Table 2 gives an overview of the means and standard deviations of these variables and the results of the $t$-tests in which both conditions are compared.

[Insert table 2 here]

No differences were found between the two writing conditions on knowledge of available writing tools incorporated in the word processor. Each student knew how to cut, copy, and paste texts and had experience using the spelling checker. However, as expected, the outline tool proved to be rather unknown. Only $10 \%$ of the respondents reported having ever used the outline tool.

No differences were found on knowledge of argumentative text structure between the two conditions. Argumentative writing was part of the students' regular curriculum and they proved to have the same prior knowledge of this genre. Participants wrote - on average - a little more than two argumentative texts a year $(M=2.23 ; S D=1.56)$. 
A difference was found between both groups regarding their use of news media. The $\mathrm{O}+\mathrm{O}+$ condition reported that they used the different media in a more extensive way than the $\mathrm{O}-\mathrm{O}+$ condition. This might produce a difference in their prior knowledge about the issue on which they wrote an argumentative text. To control for this, the variable concerning news media was used as a covariate in the remaining analyses.

No differences were found between both conditions in the extent to which students usually revise their texts. However, students in the $\mathrm{O}+\mathrm{O}+$ condition reported that they usually pay more attention to text planning. These students, therefore, might be more familiar with the conceptions underlying the outline tool (i.e., making a text plan) and thus may experience a lower barrier to using the tool and using it properly, which might eventually affect their text quality. Consequently, this variable was also used as a covariate in all data analyses.

To answer the first two research questions concerning the effect of (repeated) use of the outline tool on students' writing performance, the quality of students' written texts was analyzed and compared. Table 3 provides an overview of the means and standard deviations of the first and second writing task for both conditions.

[Insert table 3 here]

\section{Effect of Using the Outline Tool on Students' First Writing Products}

To determine the effect of using an electronic outline tool on the quality of students' writing products, text quality on the first task was compared between both conditions. The $\mathrm{O}-\mathrm{O}+$ condition carried out the first writing task without the outline tool while the $\mathrm{O}+\mathrm{O}+$ condition used the tool. The control variables 'News media-use' and 'Writing strategies: planning' were used as covariates. 


\section{Text structure}

Results of the ANCOVA test revealed a trend for the variable 'Text structure'.

Students using the outline tool for the first task tended to score higher on the structure of their texts than students who did not use the tool $\left(F(1,30)=3.29, M S E=13.00, p=.081, \eta^{2}=.11\right)$.

\section{Structure presentation}

With respect to the structure's presentation, no significant difference was found on the first writing task. Students who did not use the outline tool, did not differ significantly on structure presentation from students who did.

\section{Number of arguments}

Students who did not use the outline tool produced significantly more (sub) arguments in their first text than students who used the tool $(F(1,30)=9.28, M S E=167.63, p=.005$, $\left.\eta^{2}=.26\right)$

\section{Number of words}

Students in the O-O+ condition, tended to use more words in the final version of their first writing task than students in the $\mathrm{O}+\mathrm{O}+$ condition $(F(1,30)=3.68, M S E=47884.79$, $\left.p=.066, \eta^{2}=.12\right)$.

\section{Number of arguments and number of word per minute of writing time}

Because of the imposed division of total time, differences in the number of words and arguments might be related to differences in actual writing time. Students not using the outline tool had more writing time to elaborate their texts than students who used the tool (75 and 60 minutes respectively) and thus had more time to produce words and arguments. To make a fair comparison between the conditions, the number of words and arguments were calculated per minute of actual writing time (cf. Kellogg, 1988). These corrected data reveal no significant differences between the two conditions concerning the number of arguments and the number of words produced per minute of writing time. 


\section{Effects of Repeated Writing Tasks and Repetitive Use of the Outline Tool}

To determine whether and how text quality differs for students who use the outline tool during two consecutive tasks as compared to students who use the tool only once, task performance on the first and the second writing tasks were analysed and compared withinsubjects for both conditions. Also, performance on the second writing task was compared between the two conditions to see whether practice in writing caused an effect in product quality. Repeated use of the tool might cause differences in the quality of the second writing task.

\section{Total structure}

For the $\mathrm{O}-\mathrm{O}+$ condition, no significant difference was found for total text structure between the first and the second writing task. In addition, no significant differences were found on the four sub variables. However, results reveal a marginal improvement of body structure $(t=-1.58, p=.070, d f=13)$. In other words there is no significant increase for total text structure across both writing tasks, when using the tool only once, but there is a tendency towards an outline effect for the sub variable body structure.

In the $\mathrm{O}+\mathrm{O}+$ condition, the total text structure across the two writing tasks improved significantly $(t=-1.95, p=.037, d f=12)$. Furthermore, a significant difference was found on the structure of the sub variable conclusion $(t=-2.64, p=.011, d f=12)$, along with a trend on the improvement of the sub variable introduction $(t=-1.39, p=.095, d f=12)$. Improvement in text structure over the two writing tasks for the $\mathrm{O}+\mathrm{O}+$ condition was therefore mostly due to an improvement in the conclusion and the introduction.

Concerning the total text structure on the second task, a significant difference was found between the two conditions. Students who used the outline tool during both writing tasks scored significantly higher on the second writing task than those who used the tool only 
once $\left(F(1,25)=7.97, M S E=12.09, p=.010, \eta^{2}=.27\right)$. A significant difference was also found on the sub variable conclusion $\left(F(1,25)=7.20, M S E=4.35, p=.014, \eta^{2}=.25\right)$.

\section{Structure presentation}

For the $\mathrm{O}-\mathrm{O}+$ condition, no significant difference was found on structure presentation across the two writing tasks. However, analysis revealed a trend across both tasks for the $\mathrm{O}+\mathrm{O}+$ condition $(t=-1.62, p=.07, d f=12)$. Students who used the outline tool during both writing tasks, marginally improved their structure presentation. In other words, a marginal tool appropriation effect exists on structure presentation. Comparing the structure presentation on the second task between both conditions, no significant differences were found.

\section{Number of arguments}

Concerning the number of (sub) arguments generated across the two writing tasks, a significant increase for the O-O+ condition was observed $(t=-1.91, p=.039, d f=13)$. For the $\mathrm{O}+\mathrm{O}+$ condition, analysis showed also a significant increase in the number of arguments generated in their second text as compared to their first $(t=-3.91 p=.001 d f=12)$. No significant difference was found on the number of (sub) arguments generated on the second task between both writing conditions. However, results of the ANCOVA showed a trend in which the $\mathrm{O}-\mathrm{O}+$ condition generated marginally more arguments than the $\mathrm{O}+\mathrm{O}+$ condition $\left(F(1,25)=3.28, M S E=95.58, p=.084, \eta^{2}=.13\right)$.

\section{Number of words}

For both conditions, no significant differences were found on the number of words formulated across both writing tasks. Similarly, no significant difference was found between conditions comparing the number of words formulated in the second writing task Number of arguments and number of words per minute of writing time

When the results were recalculated per minute of actual writing time, a significant increase was found for the $\mathrm{O}-\mathrm{O}+$ condition on the number of arguments produced in the final 
text. Students produced significantly more arguments during the second writing task as compared to the first $(t=-1.81, p=.045, d f=14)$. No difference was found for the $\mathrm{O}+\mathrm{O}+$ condition on the number of generated arguments over the two tasks. A marginal difference was found comparing both conditions on the second writing task $(F(1,30)=3.11$, $\left.M S E=0.06, p=.089, \eta^{2}=.10\right)$. Students in the $\mathrm{O}-\mathrm{O}+$ condition produced marginally more arguments per minute than students in the $\mathrm{O}+\mathrm{O}+$ condition.

Analysis for the recalculated data show no differences across both writing tasks on the number of words used for both within- and between-group comparisons.

To control for possible task effects that could interfere with the effects of using the tool, a repeated measures analysis was carried out. This analysis revealed no significant differences between both conditions over both writing tasks. In other words, differences on the quality of students' written texts were not affected by task effects.

\section{Effects of Using the Outline tool on Student's Perceived Mental Effort}

Effects on mental effort on the first writing task

After each writing task, students indicated on a 5-point Likert scale how much mental effort they experienced while performing the task (see Table 4).

[Insert table 4 here]

Results of the ANCOVA reveal no significant difference between both conditions in perceived mental effort during the first writing task. However, regarding specific writing aspects, a significant difference is found on perceived mental effort when considering content accuracy: students who used the outline tool experienced significantly less mental effort formulating an accurate and correct text content than students who did not use the tool 
$\left(F(1,29)=9.90, M S E=4.63, p=.004, \eta^{2}=.28\right)$. Using the tool to make an outline in advance, reduced considerations of content during text elaboration. On all other specific writing aspects, no significant differences were found between conditions.

\section{Effects on mental effort on the second writing task}

After the second writing task, students completed the questionnaire on mental effort again. These self-report data reveal that students in the $\mathrm{O}-\mathrm{O}+$ condition experienced a significant decrease in perceived mental effort on the second writing task as compared to the first $(t=2.80, p=.008, d f=13)$. On the specific writing aspects, students in the O-O+ condition, reported a significant decrease in perceived mental effort across both writing tasks when taking content accuracy into account $(t=1.79, p=.048, d f=13)$. Moreover, they reported experiencing a marginal decrease in effort on formulating content during the second task as opposed to the first $(t=1.47, p=.083, d f=13)$. Also, they experienced a tendency towards a decrease in mental effort when determining a writing strategy $(t=1.39 p=.095$, $d f=13)$

With respect to the effects of repeated tool use on mental effort, analysis revealed that the $\mathrm{O}+\mathrm{O}+$ condition reported a marginal difference in perceived mental effort across both writing tasks $(t=1.75, p=.052, d f=13)$. On specific writing aspects, students who used the outline tool twice, reported experiencing a significant decrease in effort on determining a writing strategy across both writing tasks $(t=1.59, p=.068, d f=13)$. On all other specific ascpects, no significant differences were found.

A between-subjects analysis on the second writing task revealed that students who used the outline tool twice, experienced significantly less mental effort on taking content accuracy into account as compared to the students who used the tool once $(F(1,27)=7.02$, $\left.M S E=4.77, p=.014, \eta^{2}=.23\right)$. 


\section{Students' appropriation and appreciation of the outline tool}

After each session in which the outline tool was used, students completed a questionnaire concerning tool appropriation and appreciation. Students in the O-O+ condition used the outline tool only once, whereas students in the $\mathrm{O}+\mathrm{O}+$ condition used it twice and, thus, answered these questions twice. Table 5 gives an overview of students' experiences with the outline tool.

[Insert table 5 here]

Students reported that, after the tool instruction, they immediately understood the technical use of the outline tool. After using the tool for the first time, the $\mathrm{O}-\mathrm{O}+$ condition and the $\mathrm{O}+\mathrm{O}+$ condition scored 4.93 and 4.47 respectively on a 5-point Likert scale for technical tool understanding. This is in line with the expectation that students, as 'digital natives', would quickly be able to technically use this computer tool. In addition, the concise and abstract tool instruction was sufficient for students to understand how they could apply the tool for writing an argumentative text.

The appreciation of the outline tool and the students' opinion as to whether they would use the tool again or recommend it to a peer student or a friend varied widely. On average students were moderately positive about using the outline tool. However, after performing both writing tasks, $54 \%$ from the $\mathrm{O}+\mathrm{O}+$ condition and $69 \%$ from the $\mathrm{O}-\mathrm{O}+$ reported that they intended using the outline tool for subsequent writing tasks.

No significant differences were found between the conditions on tool appropriation and appreciation. By contrast, a significant decrease was measured for the $\mathrm{O}+\mathrm{O}+$ condition between the first and second questionnaire regarding the percentage of students that would 
recommend the outline tool to peers $(t=1.90, p=.041, d f=12)$.

\section{Students' engagement in planning strategies}

The final research question deals with whether students need to be explicitly instructed to plan their texts or whether they spontaneously devote considerable time to the planning process. In spite of the fact that the outline tool was rather unknown, students might use planning strategies other than outlining since text planning as a writing strategy is part of their regular curriculum. The data on students' division of the writing process (as percentage of the total composing time; see Table 6) allow an analysis of how students from both conditions organize their writing process. Students in the $\mathrm{O}+\mathrm{O}+$ condition were instructed to spend the first 15 minutes of the total composing time on outlining only and then write the full text in the remaining 60 minutes. For them, the division of the writing process was in large measure imposed. Students in the O-O+ condition could independently organize their writing process using the different sub processes (i.e. planning, formulating, revising).

\section{[Insert Table 6 here]}

The self-report data revealed that, during the first writing task, students in the O-O+ condition devote only $5 \%$ of the total composing time on planning their text (circa $3.5 \mathrm{~min}$ ). Students who were instructed to use the outline tool devoted $23 \%$ (circa $17.3 \mathrm{~min}$ ) of the total composing time on planning their texts. This is not surprising since they were instructed to spend 15 minutes on electronic outlining, which is one of the most recommended strategies for promoting planning (Hayes \& Nash, 1996). During the second writing task, students in the $\mathrm{O}-\mathrm{O}+$ condition were also instructed to spend 15 minutes on outlining. The data on the second writing task indeed reveal a significant increase in the percentage of time that students in the 
$\mathrm{O}-\mathrm{O}+$ devote to the planning process during the second writing task as opposed to the first $(t=-4.80, p=<.001, d f=11)$. These results show that an explicit instruction on outlining decreases students' time spent on text planning. Without an explicit instruction, students devote only a very small percentage of the composing time on the planning process.

\section{Discussion}

The two major assumptions that inspired this study were that (1) there are widely available and potentially useful computer tools that can be beneficial to learners if they were used in schools and (2) that these tools are virtually unknown and/or are generally neglected by most students. Based on these assumptions, this study hypothesizes that underuse of such tools cannot only be explained by technical competence but mostly because we are ignorant of their existence and practice. It was expected that the outline tool's straightforward nature and user-friendly design would enable students to quickly appropriate and appreciate the tool, and that it would improve their writing performance.

According to self-report data, only $10 \%$ of the respondents reported having ever used the outline tool prior to the experiment. Although this was the case, after only a brief instruction on where to find and how to use the outline tool, students reported being very confident that they understood the functioning of the outline tool. Only a short training session and the requirement to use the tool appear to be sufficient to initiate a process of appropriating the outline tool for writing. After having used the tool, a majority of the students indicated that they would use the outline tool again for subsequent writing tasks.

Given that tool-use is often largely dependent on user perceptions of its usability, utility and thus usefulness (Nielsen, 1994), the self-report data provide important indications that education may profit from such a tool for supporting student writing.

Results indicated that text quality was affected by electronic outlining in different ways. Though not significant, the first texts written by students who used the outline tool, 
tended to be more deeply structured than the first texts of students who did not use the tool. Moreover, students who used the outline tool only during the second writing task (i.e., the $\mathrm{O}-\mathrm{O}+$ condition), tended to show a higher degree of body structure in their second text than they did in their first. Even though students in this condition produced more words and arguments during the total composing time in their first text than students in the $\mathrm{O}+\mathrm{O}+$ condition, there were no differences in production between both conditions when considering the total writing time.

Concerning the effects of repeated tool use, stronger effects of the outline tool were found which is not surprising when one considers that any tool needs time and practice for effective appropriation. Students who used the outline tool twice showed an improvement in structure elaboration and structure presentation across both tasks. Moreover, the second text of students who used the outline tool for both writing tasks showed a significantly deeper structure than the second text of students who used the tool for the second task only. Taking into account the amount of time available for writing no significant differences were found between both conditions on either the number of arguments or the number of words produced per minute.

These results suggest that writing an outline with an outline tool is beneficial for organizing and structuring texts but not for generating words or arguments. As such, they contradict the results of Walvoord et al. (1995) who found that outlining was helpful for students when generating texts. It is, however, necessary to take into account that Walvoord et al. conducted a descriptive and not an experimental study. Also, it is important to realize that quantity - which is measured here in terms of number of words and arguments - is not a substitute for quality which is measured here in terms of structure and organization. Many if not most teachers would consider the latter to be more important than the former $(\operatorname{Rog} \&$ Kropp, 2004). For this reason, the positive effects of electronic outlining on text structure 
should be considered the more interesting result here. Although positive effects of students' first experience with electronic outlining do not all reach statistical significance, there are trends that may not be neglected. These trends suggest that students' investment in a new technology does not lead to a reduction of performance and risk of leaving the technology aside. This concurs with Still and Dark (2010) who found that affordance-based interactions were not affected by memory load (i.e., that the working memory's capacity was not affected by the use of a 'useful tool' and thus that learning would not be negatively affected). Under these assumptions, the use of the outline tool seems to have direct pay-offs. The fact that the positive effects on structure elaboration are most prominent for the second writing task, suggests that students profit more from electronic outlining when applying the tool more frequently (i.e., they use it better and/or learn from using it).

Along with improving a text's structure and organization, using the outline tool affected students' perceived mental effort. On the second writing task, students who had used the outline tool twice, perceived a marginal decrease in mental effort while students who used the outline tool once, reported a significant decrease in perceived mental effort across both writing tasks. The intervention of the outline tool reinforced the decrease in perceived mental effort. This might be explained by the fact that students, when constructing an outline, are more focussed on goal setting before directly formulating text. This subsequently supports them during the formulation of the text since they no longer need to focus on too many aspects at the same time, which decreased mental effort. This is a noteworthy result since cognitive load (i.e., the amount of mental effort expended while carrying out a task) is considered to be caused by the presence of novel information elements and the interactions between those elements (Kirschner, 2002). Using a new tool could cause extraneous cognitive load (i.e., load which is not directly related to the writing task, but rather needed to learn to use the tool) and one might therefore expect that the combination of using the tool and 
carrying out the writing task would lead to higher cognitive load (i.e., increased mental effort). However, the power of electronic outlining for structuring and organizing the text is apparently so great that using the tool actually decreases the total experienced mental effort. In other words the outline tool is not only effective in that leads to improved writing products, but it might also be considered efficient in that it leads to reduced mental effort.

Concerning the organization of the writing process, results indicated that students who were not explicitly instructed to make use of the outline tool, engaged hardly in any planning strategy. Instructing students to compose their text as they had learned to do in class - an instruction that included the necessity to plan- was insufficient for getting students to engage in planning strategies. This is regrettable since results show that electronic outlining leads to better structured texts. Furthermore, the perceived mental effort was lower for tasks that required the use of the outline tool.

It is important to note that students in the experiment differed widely in their appreciation of the tool. These individual differences are probably related to the degree to which students perceived profiting from electronic outlining. Kozma (1991), for example, stressed that software which supports experienced writers, may be ineffective or even harmful to writers who are still developing their writing skills, as are the participants in this experiment. For instance, using outlines in too rigid ways may prevent users from making revisions in the global text structure that are needed in the recursive process associated with writing high quality texts (see Hayes \& Flower, 1986). Thus, when introducing outline tools in education, teachers should be aware of such possible detrimental effects. Though this is the case, introducing outline tools should not be discouraged as students can be taught to use outlines more productively (Price, 1997; Walvoord et al, 1995). Moreover, students who initially are not tempted to use the strategy may find it useful after experiencing its benefits. Students may profit most from the outline tool when it is combined with effective and 
explicit instruction by teachers (i.e., an explicit combined training in outlining as a writing strategy with the aid of the electronic outline tool). When considered from a pedagogical viewpoint, the training in this experiment is a first step towards students' appropriation of the tool and learning to compose and use an outline. After teachers have given students basic information about the availability and technical use of electronic outline tools, they could explain the various functions of outlining and discuss the underlying strategy of text planning. Preferably, teachers would have a knowledge base of the most effective outline tactics for varying writing tasks at their disposal when giving instructional support. However, given the current limited availability of research on electronic outlining, teachers have to rely on exploring the value of different tactics largely by themselves, along with their students. To a certain degree such exploration will always be necessary because - like many academic strategies - outlining needs to be adapted to both personal and environmental characteristics (Alexander, Graham, \& Harris, 1998). Indeed, by discussing experiences with the outline tool with students, teachers may stimulate students' self-regulation of tool appropriation (see Butler, 1998).

A possible direction for future research could involve comparisons between several types of outline tools, including pen and paper (i.e., to answer the question of whether it is the outline tool, the outline skill, or both that cause an effect). Future research could also attempt to replicate this study and possibly generalize findings for different kinds of participants (i.e., educational or achievement levels), different types of writing tasks (e.g., argumentative, discursive, creative), different educational settings (e.g., didactic, problem based, collaborative), longitudinally (i.e., long term appropriation and effects of use), and for longterm effects (i.e., effects with tools vs. effects of tools; Kirschner \& Wopereis, 2003; Salomon, 1995).

When replicating this study, the following adaptations could be made concerning the 
methodology to insure equivocality of results found. First, the design could be expanded to include a condition where students perform both writing tasks without the outline tool. This would enable a better distinction between the effects of electronic outlining and the effects of repeated writing tasks. The present study focused on text quality measured as the elaboration and organization of argumentative texts, which is unrelated to the specific topic students had to write on. Analyses showed no significant differences concerning task effects (between both conditions over both writing tasks.). However, in future research the topics of the two writing tasks could be counterbalanced in order to control for any possible topic effects that might interfere with interpretation of outline effects for the within-subjects analysis. Of course, the statistical power of the research could be increased by increasing the size of the population and including more powerful covariates. With respect to the former, using more respondents in more classes in more schools would substantially increase the power of any results found. With respect to the latter, prior genre knowledge could be measured more directly by means of an objective test instead of a self-efficacy questionnaire. Self-efficacy measures risk students' misrepresentation of their real prior knowledge. Furthermore, the questionnaire on the writing process might be improved to obtain a more reliable variable on students' division of the writing process. Current questionnaires had a Cronbachs alpha of .60 for both the planning and the revision questionnaire which could be considered as barely adequate (DeVellis, 1991).

A concluding remark is that it would be useful to use a second, more objective measure of mental effort. Although there is much research corroborating the validity of the mental effort scale used here, there is also criticism of this measure (Brünken, Plass, \& Moreno, 2009; Kirschner, Ayres, \& Chandler, 2011). In addition to using self-report data such as the scale used here, more direct measures such as secondary task reaction times (Brünken, Plass, \& Leutner, 2003; Kellogg, 1988) could be used. 
Outlining and Argumentative Writing 31

This study indicates that electronic outlining has a great potential to improve students' writing performance, reduce mental effort and thus creates perspectives for further research on optimizing the effects of electronic outlining. 


\section{References}

Alexander, P. A., Graham, S., \& Harris, K. R. (1998). A perspective on strategy research: Progress and prospects. Educational Psychology Review, 10, 129-154.

Bereiter, C., \& Scardamalia, M. (1987). The psychology of written composition. Hillsdale, N. J.: Lawrence Erlbaum Associates.

Braaksma, M., Rijlaarsdam, G., \& Van den Bergh, H. (2009). Hypertext writing: Effects on writing processes and writing products. Paper presented at the 12th Conference of the European Association for Research on Learning and Instruction (EARLI), Budapest (Hungary), August 25-29, 2009.

Brünken, R., Plass, J., \& Leutner, D. (2003). Direct measurement of cognitive load in multimedia learning. Educational Psychologist, 38, 53-61.

Brünken, R., Plass, J., \& Moreno, R. (2009). Current issues and open questions in cognitive load research. In J. Plass, R. Moreno, \& R. Brünken (Eds.), Cognitive load theory (pp. 253-272). New York: Cambridge University Press.

Bullen, M., Morgan, T., Belfer, K., \& Qayyum, A. (2008). The digital learner at BCIT and implications for an e-strategy. Paper presented at the 2008 Research Workshop of the European Distance Education Network (EDEN), "Researching and promoting access to education and training: The role of distance education and e-learning in technologyenhanced environments", Paris, France, October 20-22.

Butler, D. L. (1998). The strategic content learning approach to promoting self-regulated learning: A report of three studies. Journal of Educational Psychology, 90, 682-697.

Chanquoy, L. (1996). Connectives and argumentative text: A developmental study. Paper presented at the First International Workshop on Argumentative Text Processing, Barcelona, Spain.

Coirier, P., Andriessen, J. E. B., \& Chanquoy, L. (1999). From planning to translating: The 
specificity of argumentative writing. In: P. Coirier \& J. E. B. Andriessen (Eds.), Foundations of argumentative text processing (pp. 1-28) Amsterdam, NL: Amsterdam University Press.

Collins, A., \& Halverson, R. (2010). The second educational revolution: Rethinking education in the age of technology. Journal of Computer Assisted Learning, 26(1) 18-27.

DeVellis, R. R. (1991). Scale development: Theory and applications. Thousand Oaks, CA: Sage

Erkens, G., Jaspers, J. G. M., Prangsma, M. E., \& Kanselaar, G. (2005). Coordination processes in computer supported collaborative writing. Computers in Human Behavior, 21, 463-486.

Erkens, G., Kanselaar, G., Prangsma, M. E., \& Jaspers, J. G. M. (2002). Using tools and resources in computer supported collaborative writing. In G. Dr. Stahl (Ed.), Computer support for collaborative learning: Foundations for a CSCL community (pp. 389-399). Hillsdale, NJ: Lawrence Earlbaum Associates.

Flower, L. S., \& Hayes, J. R, (1981). A cognitive process: Theory of writing. College Composition and Communication, 32(4), 365-387.

Flower, L. S., \& Hayes, J. R. (1984). Images, plans, and prose: The representation of meaning in writing. Written Communication, 1, 120-160.

Galbraith, D. \& Torrance, M. (2004). Revision in the context of different drafting strategies. In L. Allal, L. Chanquoy \& P. Largy (Eds.), Revision: Cognitive and instructional processes (pp. 63-86). Dordrecht, NL: Kluwer Academic Publishers.

Gopher, D., \& Braune, R. (1984). On the psychophysics of workload: Why bother with subjective measures? Human Factors, 26, 519-532.

Haas, C. (1989). How the writing medium shapes the writing process: Effects of word processing on planning. Research in the Teaching of English, 23, 181-207. 
Hayes, J. R., \& Flower, L. (1986). Writing research and the writer. American Psychologist, 41(10), 1106-1113.

Hayes, J. R., \& Nash, J. G. (1996). On the nature of planning in writing. In C. M. Levy \& S. Ransdell (Eds.), The science of writing (pp.29-55). Mahwah, New Jersey: Erlbaum.

Kellogg, R. T., (1988). Attentional overload: Effects of rough draft and outline strategies. Journal of Experimental Psychology: Learning, Memory and Cognition 14, 355-365.

Kellogg, R. T. (2008). Training writing skills: A cognitive developmental perspective. Journal of Writing Research, 1(1), 1-26.

Kieft, M. (2006). The effects of adapting writing instruction to students' writing strategies (Doctoral thesis, University of Amsterdam, Graduate School of Teaching and Learning, Amsterdam, the Netherlands). Retrieved from http://dare.uva.nl/document/29423?fid=29423

Kirschner, P. A. (2002). Cognitive load theory: Implications of cognitive load theory on the design of learning. Learning and Instruction, 12(1), 1-10.

Kirschner, P. A., Ayres, P., \& Chandler, P. (2011). Contemporary cognitive load theory research: The good, the bad and the ugly. Computers in Human Behavior, 27, 99-105.

Kirschner, P. A., \& Wopereis, I. G. J. H. (2003). Mindtools for teacher communities: A European perspective. Technology, Pedagogy and Education, 12, 107-126.

Kozma, R. B. (1991). The impact of computer-based tools and embedded prompts on writing processes and products of novice and advanced college writers. Cognition and Instruction, 8(1), 1-27.

Landis, J. R., \& Koch, G. G. (1977). The measurement of observer agreement for categorical data. Biometrics 33(1), 159-174.

Leijten, M. (2007). Writing and speech recognition. Observing error correction strategies of professional writers. Utrecht, The Netherlands: LOT. 
Margaryan, A., Littlejohn, A., Vojt, G. (2010). Are digital natives a myth or reality? University students' use of digital technologies, Computers \& Education, doi: 10.1016/ j.compedu.2010.09.004

McCutchen, D. (1987). Children's discourse skills: Form and modality requirements of schooled writing. Discourse Processes, 10(3), 267-286.

Miller, G., Galanter, E., \& Pribram, K. (1960). Plans and the structure of behavior. New York: Holt Rinehart and Winston.

Nielsen, J. (1994). Usability engineering. Cambridge, MA: Academic Press.

Paas, F. (1992). Training strategies for attaining transfer of problem-solving skill in statistics: A cognitive-load approach. Journal of Educational Psychology, 84, 429-434.

Prensky, M. (2001). Digital Natives, digital immigrants, part II: Do they really think differently? On the Horizon, 9, 1-6.

Price, J. (1997). Electronic outlining as a tool for making writing visible. Computers and Composition, 14, 409-427.

Rog, L. J. \& Kropp, P. (2004). The write genre: Classroom activities and mini-lessons that promote writing with clarity, style and flashes of brilliance. Markham, ONT: Pembroke Publishers.

Säljö, R. (2010). Digital tools and challenges to institutional traditions of learning: Technologies, social memory and the performative nature of learning. Journal of Computer Assisted Learning, 53-64.

Salomon, G. (1995). What does the design of effective CSCL require and how do we study its effects? In J. L. Schnase and E. L. Cunnius (Eds.), Proceedings of CSCL'95: The first international conference on computer support for collaborative learning. Mahwah, NJ: Lawrence A. Erlbaum.

Still, J. D., \& Dark, V. J. (2010). Examining working memory load and congruency effects on 
affordances and conventions. International Journal of Human Computer Studies, 68, $561-571$.

Turner, K. H., \& Katic, E. K. (2009). The influence of technological literacy on students' writing. Journal of Educational Computing Research, 41, 253-270.

University of Chicago (2003). The Chicago manual of style (15th ed.). Chicago: University of Chicago Press.

Walvoord, B. E., Anderson, V. J., Breihan, J. R., McCarthy, L. P., Robison, S. M., \& Sherman, A. K. (1995). Functions of outlining among college students in four disciplines. Research in the Teaching of English, 29, 390-421. 


\section{Appendix 1}

\section{Assessment sheet}

\begin{tabular}{|l|l|l|l|l|}
\hline Name respondent & Class & Outline & Task & No. of words \\
\hline & & Y / N & $1 / 2$ & \\
\hline
\end{tabular}

\begin{tabular}{|c|c|c|c|}
\hline Category & Questions & Points & Total \\
\hline \multirow[t]{5}{*}{ A. Text structure } & $\begin{array}{l}\text { Does the text contain a title? } \\
\text { If no, } 0 \text { points. If yes, } 1 \text { point. }\end{array}$ & $0-1$ & Title: \\
\hline & $\begin{array}{l}\text { Does the text contain an introduction? } \\
\text { Does the introduction attract the reader? } \\
\text { Is the topic made explicit? } \\
\text { Is the problem defined? } \\
\text { Are the different positions introduced? } \\
\text { Is the writer's own position stated? }\end{array}$ & $\begin{array}{l}0-1 \\
0-1 \\
0-1 \\
0-1 \\
0-1 \\
0-1\end{array}$ & Introduction: \\
\hline & $\begin{array}{l}\text { Does the text contain a body? } \\
\text { Are there arguments stated to support the writer's position? } \\
\text { Are the arguments supported by examples? } \\
\text { Are there counter arguments stated? } \\
\text { Are the counter arguments refuted? }\end{array}$ & $\begin{array}{l}0-1 \\
0-1 \\
0-1 \\
0-1 \\
0-1\end{array}$ & Body: \\
\hline & $\begin{array}{l}\text { Does the text contain a conclusion? } \\
\text { Are the main arguments summarized? } \\
\text { Is the reader encouraged to take action? } \\
\text { Is there a powerful clincher? }\end{array}$ & $\begin{array}{l}0-1 \\
0-1 \\
0-1 \\
0-1\end{array}$ & Conclusion: \\
\hline & & & A: \\
\hline B. Structure presentation & $\begin{array}{l}\text { Is the division into paragraphs sufficient? } \\
\text { Is the division into paragraphs correct? } \\
\text { Have connectives been used sufficiently? } \\
\text { Have connectives been used correctly? } \\
\text { Is the tone of voice appropriate for the intended audience? } \\
\text { Does the writer consider the position, attitude and values of others? } \\
\text { Does the writer succeed in showing his of her enthusiasm and } \\
\text { commitment to the topic? }\end{array}$ & 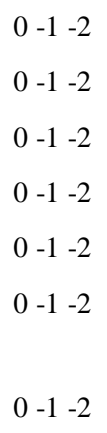 & B: \\
\hline $\begin{array}{l}\text { C. Elaboration of } \\
\text { argumentation }\end{array}$ & $\begin{array}{l}\text { How many (sub) arguments are stated in the text? } \\
\text { Average score for hierarchical elaboration of the main arguments } \\
\text { No elaboration (0) } \\
\text { Elaboration in sub arguments (1) } \\
\text { Elaboration in sub sub arguments (2) } \\
\text { Clarity of the main arguments } \\
\text { Persuasiveness of main arguments }\end{array}$ & $\begin{array}{l}0-1-2 \\
0-1-2\end{array}$ & C: \\
\hline
\end{tabular}


Outlining and Argumentative Writing 38

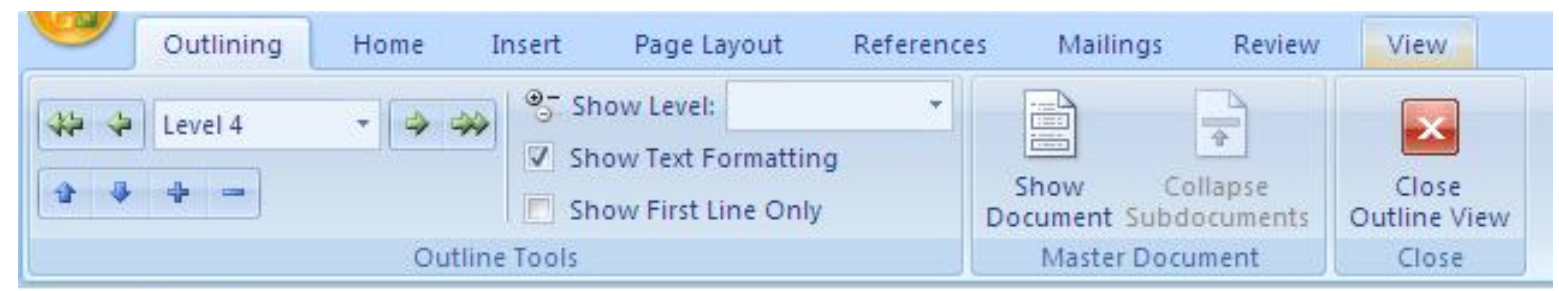

$\oplus$ Our house

(†) Downstairs

Corridor

$\oplus$ Living room

$\odot$ Sofa

Easychair

Figure 1. Screenshot of the outline tool within Microsoft Office Word $2007^{\circledR}$ 
Outlining and Argumentative Writing 39

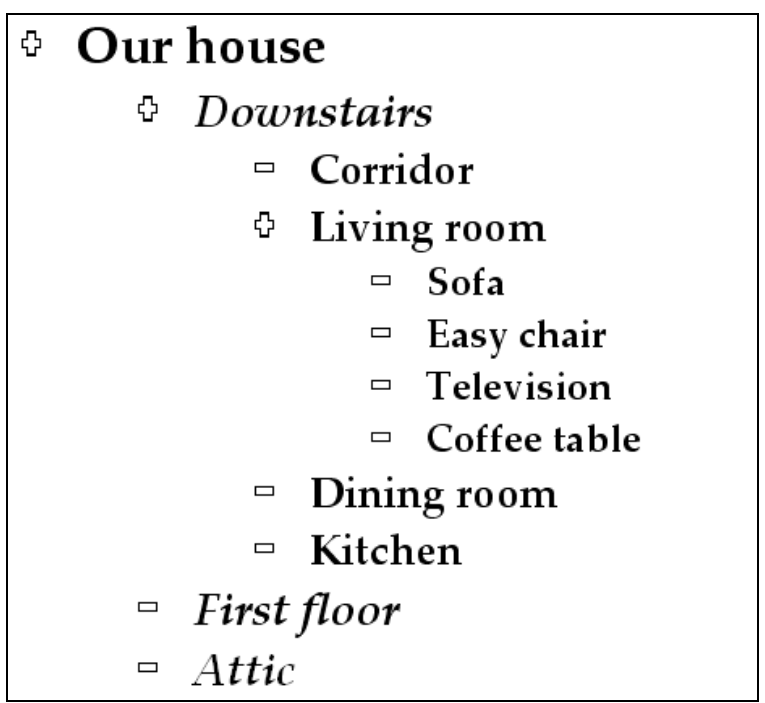

Figure 2. Example Outline Developed by the Instructor during the Outline Tool Training. 


\begin{tabular}{|l|l|l|}
\hline O-O+ condition $(n=18)$ & Task 1: No outline tool & Task 2: Outline tool \\
\hline $\mathrm{O}+\mathrm{O}+$ condition $(\mathrm{n}=16)$ & Task 1: Outline tool & Task 2: Outline tool \\
\hline
\end{tabular}

Figure 3. Design of the Study. O+ = With Outline Tool; O- = Without Outline Tool 
Table 1

Inter-rater Reliability on Product Evaluation

\begin{tabular}{lcc}
\hline Evaluated item & Cohen's Kappa & Spearman's $r$ \\
\hline Text structure & - & .84 \\
$\bullet \quad$ Title & 1.00 & 1.00 \\
$\bullet \quad$ Introduction & .77 & .90 \\
$\bullet \quad$ Body & .80 & .75 \\
$\bullet \quad$ Conclusion & .65 & .78 \\
Structure presentation & - & .87 \\
Number of arguments & - & .81 \\
Hierarchical elaboration of arguments & - & .35 \\
\hline
\end{tabular}


Outlining and Argumentative Writing 42

Table 2

Means, Standard Deviations and T-test results of the Control Variables for both conditions

\begin{tabular}{lccccc}
\hline & $M(S D) O-O+$ & $M(S D) O+O+$ & $d f$ & $t$ & $p$ \\
\hline Knowledge of available writing tools $(\max =12)$ & $8.75(1.84)$ & $8.94(1.39)$ & 30 & -0.33 & .748 \\
Knowledge of argumentative text structure $(\max =65)$ & $46.88(8.82)$ & $47.75(6.27)$ & 30 & -0.23 & .749 \\
News media use $(\max =30)$ & $12.00(4.34)$ & $15.44(4.30)$ & 30 & -2.25 & .032 \\
Usual writing strategies : Planning $(\max =20)$ & $9.19(3.02)$ & $12.38(2.47)$ & 30 & -3.27 & .003 \\
Usual writing strategies: Revision $(\max =30)$ & $20.94(4.93)$ & $20.81(3.23)$ & 30 & 0.09 & .933 \\
\hline
\end{tabular}


Table 3

Means and Standard Deviation of Text Quality on Task 1 and Task 2

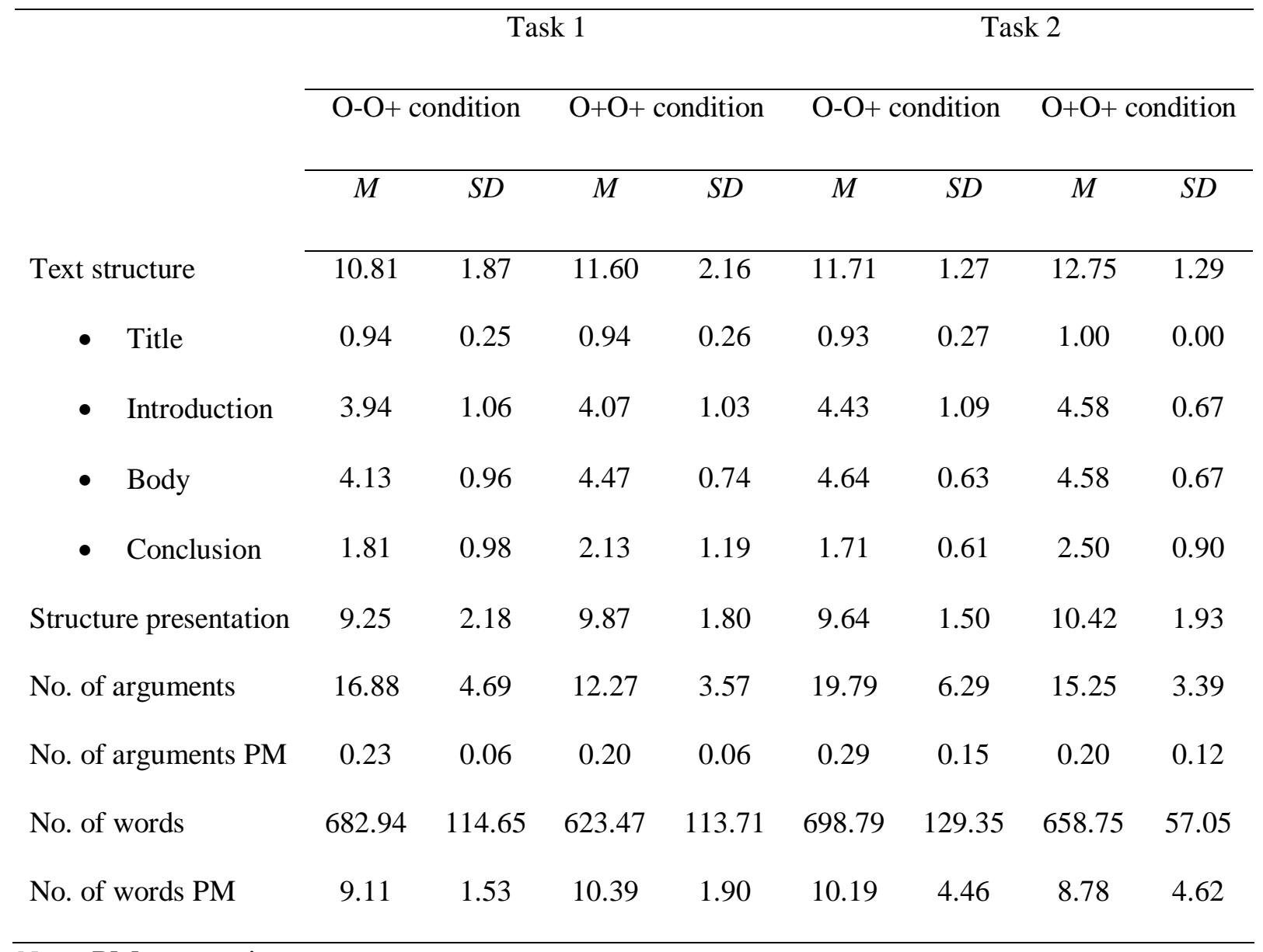

Note. $\mathrm{PM}=$ per minute 
Table 4

Means and Standard Deviations of Mental Effort

\begin{tabular}{|c|c|c|c|c|c|c|c|c|}
\hline & \multicolumn{4}{|c|}{ Task 1} & \multicolumn{4}{|c|}{ Task 2} \\
\hline & \multicolumn{2}{|c|}{$\mathrm{O}-\mathrm{O}+$ condition } & \multicolumn{2}{|c|}{$\mathrm{O}+\mathrm{O}+$ condition } & \multicolumn{2}{|c|}{$\mathrm{O}-\mathrm{O}+$ condition } & \multicolumn{2}{|c|}{$\mathrm{O}+\mathrm{O}+$ conditior } \\
\hline & $M$ & $S D$ & $M$ & $S D$ & $M$ & $S D$ & $M$ & $S D$ \\
\hline General mental effort & 3.63 & 1.02 & 3.20 & 0.94 & 3.00 & 0.55 & 2.62 & 0.77 \\
\hline \multicolumn{9}{|l|}{ Specific effort on: } \\
\hline - Content & 3.19 & 0.98 & 2.93 & 1.16 & 3.14 & 0.66 & 2.85 & 1.07 \\
\hline - Strategy & 3.06 & 0.77 & 3.13 & 1.06 & 2.79 & 0.43 & 2.69 & 0.95 \\
\hline - Structure & 2.88 & 0.62 & 2.73 & 1.22 & 2.86 & 0.66 & 2.85 & 1.07 \\
\hline - Dividing paragraphs & 3.00 & 1.03 & 2.67 & 1.23 & 2.61 & 0.51 & 2.85 & 1.07 \\
\hline - Sentence structure & 2.69 & 0.87 & 2.60 & 0.91 & 2.79 & 0.58 & 2.69 & 0.85 \\
\hline - Spelling & 2.63 & 0.81 & 2.53 & 1.36 & 2.64 & 0.75 & 2.54 & 1.05 \\
\hline - Content accuracy & 3.56 & 0.63 & 2.43 & 0.76 & 3.21 & 0.80 & 2.38 & 0.87 \\
\hline - Reader orientation & 3.06 & 0.77 & 2.60 & 1.06 & 3.00 & 0.68 & 2.62 & 1.04 \\
\hline - Lay-out & 2.44 & 0.73 & 2.29 & 0.91 & 2.64 & 0.74 & 2.31 & 0.85 \\
\hline
\end{tabular}

Note. All scales range from $1=$ very little effort through $5=$ very much effort 
Table 5

Students' Appropriation and Appreciation of the Outline Tool

\begin{tabular}{|c|c|c|c|c|c|c|}
\hline & \multirow{2}{*}{\multicolumn{2}{|c|}{$\begin{array}{c}\text { Task } 1 \\
\mathrm{O}+\mathrm{O}+\text { condition }\end{array}$}} & \multicolumn{4}{|c|}{ Task 2} \\
\hline & & & $\mathrm{O}-\mathrm{O}+$ & lition & $\mathrm{O}+\mathrm{O}-$ & dition \\
\hline & $M$ & $S D$ & $M$ & $S D$ & $M$ & $S D$ \\
\hline Understand tool $(\max =5)$ & 4.47 & 1.06 & 4.93 & 0.27 & 4.54 & 1.12 \\
\hline Understand applying tool $(\max =5)$ & 4.27 & 1.16 & 4.36 & 0.84 & 4.31 & 1.18 \\
\hline Benefit of outline $(\max =5)$ & 3.00 & 1.31 & 3.50 & 1.16 & 2.85 & 1.28 \\
\hline Use outline again $(\max =1)$ & 0.40 & 0.51 & 0.69 & 0.48 & 0.54 & 0.52 \\
\hline Recommend outline $(\max =1)$ & 0.53 & 0.52 & 0.50 & 0.38 & 0.38 & 0.51 \\
\hline
\end{tabular}


Outlining and Argumentative Writing 46

Table 6

Mean Percentages and Standard Deviations of the Total Writing Process' Time

Task 1

Task 2

\begin{tabular}{cccccccc}
\hline O-O+ condition & O+O+ condition & O-O+ condition & O+O+ condition \\
& & & & & & \\
\hline$M$ & $S D$ & $M$ & $S D$ & $M$ & $S D$ & $M$ & $S D$
\end{tabular}

Planning

\begin{tabular}{cccccccc}
\hline 4.67 & 5.08 & 23.00 & 18.88 & 19.23 & 8.62 & 15.38 & 10.30 \\
89.60 & 10.90 & 63.00 & 20.86 & 75.77 & 8.86 & 60.38 & 22.95 \\
5.73 & 7.18 & 14.00 & 12.71 & 5.00 & 4.56 & 24.23 & 21.88
\end{tabular}

Formulating

Revising

(1.00

